\title{
Does Trading Activity of China's A-Share Improve after the Inclusion of China's A-Share in the MSCI Index?
}

\author{
Hongbin Deng \\ School of Economics, Jinan University, Guangzhou, China \\ Email: robin_dum@163.com
}

How to cite this paper: Deng, H. B. (2021). Does Trading Activity of China's A-Share Improve after the Inclusion of China's A-Share in the MSCI Index? Journal of Service Science and Management, 14, 34-44.

https://doi.org/10.4236/jssm.2021.141003

Received: January 3, 2021

Accepted: February 5, 2021

Published: February 8, 2021

Copyright $\odot 2021$ by author(s) and Scientific Research Publishing Inc. This work is licensed under the Creative Commons Attribution International License (CC BY 4.0).

http://creativecommons.org/licenses/by/4.0/

\begin{abstract}
This paper mainly studies whether the inclusion of China's A-shares in the MSCI (Morgan Stanley Capital International) index improved the trading activity. Taking all China's A-share stocks as samples and using the trading data of four years from 2016 to 2019, this paper designs corresponding Difference-in-Difference models and conducts empirical research. It is found that the inclusion of MSCI index does reduce the turnover rate of stocks and the level of activity in stock trading decrease. Two reasons account for this: on the one hand, institutional investors with more long-term capital and more robust investment styles have entered into A-share market; on the other hand, investors have become relatively more consistent in the value of the MSCI component stocks because of the highly recognition of global capital markets.
\end{abstract}

\section{Keywords}

Turnover Rate, MSCI Index, Stock Market, Level of Trading Activity

\section{Introduction}

In recent years, China has been pushing forward steadily the process of opening up its capital market and carried out successively RQDII, "Shanghai-Hong Kong Stock Connect" and "Shenzhen-Hong Kong Stock Connect". Especially, it is announced that China's A-shares will be included into the MSCI index, which is undoubtedly a milestone event in the process of China's capital market opening to the outside world.

The inclusion of MSCI index is of great significance for China's securities market. MSCI index is compiled by Morgan Stanley Capital International Cor- 
poration and it is regarded as an important indicator of international capital. More than 9.5 trillion dollars of assets around the world track the index and $97 \%$ of the top asset management companies take MSCI index for main reference when they makes decisions. After China's A-shares are officially included in the MSCI index in June 2018, its' weight will gradually increase in the MSCI index according to the expansion schedule. Affected by this, there will be a large number of international capital flow into China's securities market, and the relationship between China's capital market and the international capital market will be more closely.

So far, there have been a lot of studies on the impact of inclusion in MSCI index on A-shares, mainly focusing on the impact on stock price volatility and return rate, as well as testing the announcement effect and stock price information content of this event. Besides, in addition to these empirical literatures, many earlier scholars also conducted extensive qualitative analysis and discussion on the advantages and disadvantages of A-shares being included in MSCI index. Different from that, this paper mainly focuses on whether the inclusion of MSCI index will increase the activity of A-share market since it can bring a lot of funds and is more closely connected to international capital. It is worth noting that the A-share list has experienced five times of changes from June 2017 when it was announced that it would be included in the MSCI index, to June 2018 when it was officially included, and then to 2019 when its capacity was expanded three times. This paper will use the Difference-in-Difference models to track whether there is a significant change of component stocks on the stock trading activity before and after the announcement of list, and then analyze the potential reasons behind it.

The main contribution of this paper is to provide a new empirical case to the research field of "the impact of inclusion of MSCI index on China A-shares" by studying the changes of stock trading activity before and after the inclusion of China A-share in MSCI index for totally five times in the past three years.

The structure of remaining article is as follows: the second part is literature review; the third part is the data \& models; the fourth part is the empirical results \& analysis; the last part is the conclusion \& policy recommendations.

\section{Literature Review}

Relevant researches on the impact of MSCI index on stock market mainly focus on the empirical research of stock price volatility and return rate. In terms of volatility, Gaetano (2018) analyzed and studied the impact of structural changes on the daily return volatility of securities markets in five BRICS countries (China, Russia, Brazil, India and South Africa). The research results of Li Jiangping (2018) showed that the overall level of stock prices in the market dropped significantly after the implementation of the Shenzhen-Hong Kong Stock Connect policy. Jitendra Singh et al. (2018) studied the correlation between the fluctuations of commodity index and MSCI index. Joyo \& Lefen (2019) studied the 
time-varying correlation and volatility between developed markets (UK and US) and emerging markets (China, Malaysia and Indonesia) and the stock market of Pakistan respectively. In terms of return rate, Kong Yuwen (2018) used the event study method and found that the announcement of A-share "inclusion into MSCI index" event had the most significant impact on the abnormal return of stock prices in the consumer and financial industries. Chen Tianyou (2019) measured the average excess returns of the SSE Composite Index and MSCI conceptual index during the event window period, and found that two events produced significant positive effects on the two indexes, while the other three events did not observe significant effects.

In addition to these empirical literatures, many scholars also conducted extensive qualitative analysis and discussion on the advantages and disadvantages of A-shares being included in MSCI index. Guo Shiliang (2019) believes that A-shares "inclusion into MSCI index" can not only bring a lot of incremental funds to the stock market, but also effectively improve the investor structure and further promote the internationalization and marketization of finance. E Zhihuan and Su Jie (2017) pointed out that the optimization of investor structure will effectively guide the investment concept, way and style of China's stock market, and make it more stable and mature. Wei Zhen (2017) proposed that "inclusion into MSCI index" could promote the launch of risk management tools and financial derivatives, and at the same time, it would urge the transparency and internationalization of corporate governance. Ge Feng (2018) pointed out that the inclusion of A-shares in MSCI index is more important to accelerate the improvement of all aspects of the system of China's securities market. Although the vast majority of articles are about the positive evaluation of A-shares "inclusion into MSCI index", but also a few scholars point out that we need to pay attention to the problem after inclusion into MSCI index. Mo Kaiwei (2018) emphasized that the A-share "inclusion into MSCI index" is not only an opportunity, but also a challenge. Considering the huge difference in investment level between Chinese investors and international institutional investors, we need to deal with all kinds of risks and challenges prudently, seek advantages and avoid disadvantages, so as to share the dividends brought by "A-shares' inclusion into MSCI index".

All in all, a large number of papers have studied the different aspects of influence on the inclusion in MSCI index on A-shares. Among them, however, there is very little attention paying on the effect of A-share market's activity after including into MSCI index, which is exactly the issue this paper focuses on.

In the previous literature, the turnover rate was used to measure the stock trading activity. Representative literature included Datar et al. (1998); Brennan et al. (1998); Chordia et al. (2001); Su Dongwei and Mai Yuanxun (2004); Zhang Zheng and Liu Li (2006); and so on. Following these references, this paper also takes turnover rate as a measure of stock market activity to conduct an empirical research. 


\section{Data and Models}

\subsection{Data}

This paper mainly studies whether the inclusion of MSCI index has improved the activity of China's A-shares. Correspondingly, this paper takes all stocks of A-shares whose trading data can be collected as full sample. Among them, the sample of treatment group is all stocks of China A-shares that have entered or withdrawn from the list of stocks in MSCI index in recent three years. The time period of the sample is from January 1, 2016 to December 31, 2019 (four years before and after the inclusion of the MSCI index). All the variables are daily frequency data. All data in this article are from database of CSMAR and Shenzhen Tinysoft Technology Company.

Table 1 shows the time schedule when the list of component stocks has been adjusted and changed, which is critical time node that this paper focuses on. In order to eliminate the noise caused by market expectation and make the analysis result more accurate, this paper will push forward 20 days in Table 1 to study the change of stock activity, which mainly refers to the practice of Easley et al. (2001). In addition, this paper follows the previous and traditional literature to measure the stock activity by the turnover rate, with a total of 4,115,475 data of 4221 stocks in the sample.

\subsection{Descriptive Statistical Results}

Table 2 is the descriptive statistical results of the turnover rate of the stocks of the treatment group and the control group within half a year before and after the publication of the list of MSCI component stocks. It can be seen from it that although the mean turnover rate of both the treatment group and the control group increased after the first list was published, the mean turnover rate of all the remaining four lists decreased. It is worth noting that although the mean turnover rates of both the treatment group and the control group increased after the first list was published, the increase of the treatment group was much smaller than that of the control group, with an increase of about 0.03 and 0.15 respectively. Accordingly, the mean in treatment group and control group in the following four times is reduced, and can be seen obviously in treatment group the average decrease rate is much larger than the control group (the only exception is the third time in the list published in post-processing group and control group average decline is almost the same, about 0.28 ).

Table 1. Announcement schedule of list.

\begin{tabular}{cc}
\hline NO. & Announcement time \\
\hline first list & June 21, 2017 \\
second list & May 15, 2018 \\
third list & May 14, 2019 \\
fourth list & August 8, 2019 \\
fifth list & November 8, 2019 \\
\hline
\end{tabular}


Table 2. Descriptive statistical results.

\begin{tabular}{ccccccc}
\hline \multirow{2}{*}{ Variable } & \multirow{2}{*}{ Treat } & \multicolumn{2}{c}{ Treatment Group } & \multicolumn{2}{c}{ Control Group } \\
\cline { 4 - 7 } first list & & & Mean & SD & Mean & SD \\
\hline \multirow{3}{*}{ second list } & turnover & before & 0.889 & 1.409 & 1.961 & 4.485 \\
& turnover & after & 0.922 & 1.144 & 2.109 & 4.508 \\
& turnover & before & 1.550 & 2.070 & 2.054 & 4.600 \\
& turnover & after & 1.290 & 2.091 & 1.868 & 4.227 \\
\multirow{3}{*}{ third list } & turnover & before & 1.178 & 1.452 & 2.547 & 4.266 \\
& turnover & after & 0.900 & 1.073 & 2.269 & 4.255 \\
& turnover & before & 1.409 & 1.706 & 2.715 & 4.413 \\
fourth list & turnover & after & 0.590 & 0.475 & 2.213 & 4.263 \\
& turnover & before & 3.275 & 4.776 & 2.296 & 4.274 \\
\multirow{2}{*}{ fifth list } & turnover & after & 2.139 & 2.655 & 2.109 & 4.059 \\
\hline
\end{tabular}

By comparing the difference in amplitude of variation of turnover rate between the treatment group and the control group before and after the list was published, the following conjectural can be preliminarily made: stock trading activity decreased after inclusion in the MSCI index. Of course, since we did not consider the influence of other factors on the turnover rate, the conclusion drawn by descriptive statistical results is still very crude.

Therefore, this paper will further use the Difference-in-Difference models to make a more accurate assessment of "whether the inclusion of MSCI index will increase the stock activity", and explore the reasons and mechanisms behind it.

\subsection{Models}

Following the idea of Beck et al. (2010), this paper designs the DID static model and dynamic model respectively. The former is the traditional DID model, which aims to investigate the overall effect of policies. The latter is a multi-time DID model, which aims to investigate the effect of phased policies (or, the dynamic effect of policies) and test the parallel trend hypothesis of the DID model.

The static model of this paper is as following:

$$
\text { turnover }_{i t}=\beta_{0}+\beta_{1} \text { treat }_{i t}+A_{i t}+\mu_{i}+\gamma_{t}+\epsilon_{i t}
$$

where the turnover $_{i t}$ is the turnover rate of individual $i$ in the period $t$. treat $_{i t}$ is the treatment variable, which takes the value of 1 if the stock is on the list and the period is locating after the MSCI index list is published; and take 0 at other cases. $A_{i t}$ is the control variable, referring to the previous literature, specifically including the stock price, logarithm of trading volume and logarithm of company market capitalization; $\mu_{i}$ and $\gamma_{t}$ are individual fixed effect and time fixed effect respectively; $\epsilon_{i t}$ is the disturbance term. In the two coefficients, $\beta_{0}$ is the intercept term, and $\beta_{1}$ is the overall change of the stock turnover rate after the inclusion of MSCI index, representing the total effect of the policy. 
The dynamic model of this paper is as following:

$$
\begin{aligned}
\text { turnover }_{i t}= & \beta_{0}+\beta_{1} \text { treat }_{i t}^{-4}+\beta_{2} \text { treat }_{i t}^{-3}+\beta_{3} \text { treat }_{i t}^{-2}+\beta_{4} \text { treat }_{i t}^{0}+\beta_{5} \text { treat }_{i t}^{1} \\
& +\beta_{6} \text { treat }_{i t}^{2}+\beta_{7} \text { treat }_{i t}^{3}+\beta_{8} \text { treat }_{i t}^{4}+A_{i t}+\mu_{i}+\gamma_{t}+\epsilon_{i t}
\end{aligned}
$$

where the treat $_{i t}^{-j}$ takes the value of 1 if the stock is on the list and the period is locating at period $j$ before the MSCI index list is published, and take 0 at other cases. Similarly, $\operatorname{treat}_{i t}^{j}$ takes the value of 1 if the stock is on the list and the period is locating at period $j$ after the MSCI index list is published, and take 0 at other cases. The meaning of the remaining items is consistent with the static model. The model takes the period that one-period-ahead of announcement time as the base period, so formula (2) does not add the item " treat $_{i t}^{-1}$ ".

\section{Empirical Results and Analysis}

Based on the data and econometric model specified in the third part, the empirical results of the static model and the dynamic model can be calculated respectively using the software of Stata.

The empirical results of the static model are shown in Table 3. In order to ensure the robustness of the results, various possible scenarios are presented in Table 3: the first is whether the control variables exist or not? The second is whether the fixed effect is controlled? If the answer is yes, then the time fixed effect is controlled to the season or year? The third is whether the clustering standard error is controlled to individual or industry. The reason why we do like this is that, if the results are in line with expectations in all circumstances, then was not caused by man-made subjective chose some special control variables, human subjective control for a particular time fixed effects and clustering of subjective chose some special standard error which leads to a certain ideal results.

\begin{tabular}{|c|c|c|c|c|c|c|c|c|}
\hline & (1) & (2) & (3) & (4) & (5) & (6) & (7) & (8) \\
\hline & Basic_id & Basic_ind & Basic_season_id & Basic_year_id & $\begin{array}{c}\text { Control } \\
\text { _season_id }\end{array}$ & $\begin{array}{c}\text { Control } \\
\text { _year_id }\end{array}$ & $\begin{array}{c}\text { Control } \\
\text { _season_ind }\end{array}$ & $\begin{array}{l}\text { Control } \\
\text { _year_ind }\end{array}$ \\
\hline \multirow[t]{2}{*}{ treat } & $-0.249^{\star * \star}$ & $-0.384^{\star \star \star}$ & $-0.396^{\star * *}$ & $-0.403^{\star * \star}$ & $-0.214^{\star \star}$ & $-0.256^{\star * *}$ & $-0.273^{\star *}$ & $-0.307^{\star \star}$ \\
\hline & $(-5.01)$ & $(-4.97)$ & $(-6.20)$ & $(-6.55)$ & $(-2.30)$ & $(-2.81)$ & $(-2.14)$ & $(-2.33)$ \\
\hline \multirow[t]{2}{*}{ price } & & & & & $0.055^{\star *}$ & $0.055^{\star *}$ & $0.055^{*}$ & $0.056^{*}$ \\
\hline & & & & & $(2.07)$ & $(2.08)$ & $(1.90)$ & (1.91) \\
\hline \multirow[t]{2}{*}{$\operatorname{lnmv}$} & & & & & 0.115 & 0.140 & 0.154 & 0.172 \\
\hline & & & & & $(0.35)$ & $(0.43)$ & $(0.48)$ & $(0.54)$ \\
\hline \multirow[t]{2}{*}{ lntravol } & & & & & $2.875^{\star * *}$ & $2.874^{\star * *}$ & $2.953^{* * *}$ & $2.950^{\star * *}$ \\
\hline & & & & & $(84.94)$ & $(85.52)$ & $(22.67)$ & $(22.44)$ \\
\hline control variables & no & no & no & no & yes & yes & yes & yes \\
\hline fix effect & no & no & yes & yes & yes & yes & yes & yes \\
\hline cluster standard error & id & industry & id & id & id & id & industry & industry \\
\hline$N$ & $4,115,475$ & $3,732,586$ & $4,115,475$ & $4,115,475$ & $3,088,502$ & $3,088,502$ & $3,079,906$ & $3,079,906$ \\
\hline
\end{tabular}

Table 3. Static model-newly enter in.

$t$ statistics in parentheses; ${ }^{*} p<0.1,{ }^{* *} p<0.05,{ }^{* * *} p<0.01$. 
As we can see from the results in Table 3, in all the above possible cases, the main variable concerned in this paper $\beta_{1}$, the coefficient of treat, are all negative, and all of them are significant at the level of $99 \%$ or $95 \%$, indicating that the results are relatively robust and highly reliable. Specifically, with no control variables, the coefficients are between -0.25 and -0.40 ; however, when there are control variables, the coefficient $\beta_{1}$ is between -0.21 and -0.31 , the fluctuation is acceptable. Of course, this paper believes that the more accurate estimation result should be the one with the control variables, the time fixed effect controlled to the season and the clustering to the industry, which is present in column (7) “- -0.273 ", indicating that the turnover rate decreased by 0.273 on average after the inclusion of MSCI index under the same other conditions. Noting that in the descriptive statistical results of the third part, the average turnover rate of all samples is between 0.9 and 3. So, relatively speaking, " 0.273 " is already a considerable number, which is equivalent to a decrease of about $9 \%$ to $30 \%$ in turnover.

Noting that when the list was adjusted and published, there were not only "stocks that had not entered the list before but were newly entered in this time", but also "stocks that had entered the list before but were removed off this time". The treatment group of DID model in Table 3 is newly entered in stocks. It is found that the turnover rate of newly entered stocks decreases significantly after they are included in MSCI index. Further, we want to ask whether "the change in turnover rate of stocks that have been just removed from the MSCI index" present the opposite outcome of "the change of stocks that have just been introduced".

Empirical results in Table 4 answer the question above. The treatment group of DID model in Table 4 is the newly kick-off stocks. As can be seen from the

Table 4. Static model-newly kick off.

\begin{tabular}{|c|c|c|c|c|c|c|}
\hline & $(1)$ & (2) & (3) & (4) & (5) & (6) \\
\hline & Basic_season_ind & Basic_year_ind & Control_season_id & Control_year_id & Control_season_ind & Control_year_ind \\
\hline \multirow[t]{2}{*}{ treat } & $0.551^{\star *}$ & $0.396^{* *}$ & $0.461^{* *}$ & $0.430^{* *}$ & $0.417^{\star}$ & $0.394^{*}$ \\
\hline & $(2.61)$ & $(2.20)$ & $(2.22)$ & $(2.07)$ & $(1.89)$ & $(1.77)$ \\
\hline \multirow[t]{2}{*}{ price } & & & $0.054^{\star *}$ & $0.055^{\star *}$ & $0.055^{\star}$ & $0.055^{*}$ \\
\hline & & & $(2.05)$ & $(2.05)$ & $(1.88)$ & $(1.88)$ \\
\hline \multirow[t]{2}{*}{$\ln m v$} & & & 0.097 & 0.123 & 0.131 & 0.152 \\
\hline & & & $(0.29)$ & $(0.38)$ & $(0.41)$ & $(0.48)$ \\
\hline \multirow[t]{2}{*}{ lntravol } & & & $2.875^{\star * \star}$ & $2.874^{\star * *}$ & $2.953^{* * *}$ & $2.950^{\star * *}$ \\
\hline & & & $(84.79)$ & $(85.35)$ & $(22.64)$ & $(22.42)$ \\
\hline control variables & no & no & yes & yes & yes & yes \\
\hline fix effect & yes & yes & yes & yes & yes & yes \\
\hline cluster standard error & industry & industry & id & id & industry & industry \\
\hline$N$ & $3,732,586$ & $3,732,586$ & $3,088,502$ & $3,088,502$ & $3,079,906$ & $3,079,906$ \\
\hline
\end{tabular}

$t$ statistics in parentheses; ${ }^{*} p<0.1,{ }^{* *} p<0.05,{ }^{* * *} p<0.01$. 
table, no matter whether there is a control variable or not, no matter whether the time fixed effect is controlled to the quarter or year, no matter whether the clustering standard error is controlled to the individual or the industry, the main variable concerned in this paper $\beta_{1}$, the coefficient of treat, are all positive, and all of them are significant at the level of $95 \%$ or $90 \%$. Specifically, in the presence of control variables, the coefficients are between 0.39 and 0.46 . Of course, this paper believes that the more accurate estimation result should be the result of the existence of control variables, the time fixed effect controlled to the quarter and the clustering to the industry. That is exactly the result in column (5) " 0.417 ", indicating that the turnover rate increases by 0.417 on average after being removed from the list of MSIC index under the same other conditions. This further supports the empirical results in Table 3, indicating that the positive coefficient $\beta_{1}$ in Table 3 is indeed caused by the factor of "inclusion of MSCI index". So, the inclusion of MSCI index does significantly reduce the turnover rate.

The empirical results discussed so far have been estimated by the DID models constructed in the third part. However, only when certain presuppositions are satisfied can the results of the DID model be highly reliable. The most important presupposition of DID model is the parallel trend. In order to test whether this hypothesis is valid or not, it is necessary to further examine the empirical results of the dynamic DID model, as shown in Table 5.

Table 5. Result of dynamic model.

\begin{tabular}{|c|c|c|c|c|c|}
\hline \multirow[t]{2}{*}{ Interval } & \multicolumn{3}{|c|}{ Semi-annual } & \multirow{2}{*}{$\begin{array}{c}\text { Season } \\
(4)\end{array}$} & \multirow{2}{*}{$\begin{array}{c}\text { Week } \\
(5)\end{array}$} \\
\hline & (1) & (2) & (3) & & \\
\hline \multirow[t]{2}{*}{ treat_4 } & $-0.393^{\star *}$ & -0.228 & -0.284 & 0.027 & 0.037 \\
\hline & $(-1.99)$ & $(-1.52)$ & $(-1.41)$ & $(0.25)$ & $(0.39)$ \\
\hline \multirow[t]{2}{*}{ treat_3 } & -0.071 & 0.021 & 0.050 & 0.088 & 0.010 \\
\hline & $(-0.33)$ & $(0.09)$ & $(0.23)$ & $(1.09)$ & $(0.12)$ \\
\hline \multirow[t]{2}{*}{ treat_2 } & 0.110 & 0.047 & $0.182^{*}$ & 0.090 & 0.016 \\
\hline & $(1.19)$ & $(0.38)$ & $(1.86)$ & $(1.14)$ & $(0.18)$ \\
\hline \multirow[t]{2}{*}{ treat_1 } & 0.046 & -0.071 & 0.107 & -0.037 & -0.119 \\
\hline & $(0.73)$ & $(-0.91)$ & $(1.57)$ & $(-0.67)$ & $(-1.44)$ \\
\hline \multirow[t]{2}{*}{ treat1 } & $-0.206^{* * *}$ & $-0.349^{* * *}$ & $-0.177^{* * *}$ & $-0.112^{* *}$ & $-0.164^{* *}$ \\
\hline & $(-3.65)$ & $(-4.79)$ & $(-2.99)$ & $(-2.21)$ & $(-2.05)$ \\
\hline \multirow[t]{2}{*}{ treat2 } & $-0.254^{* * *}$ & $-0.384^{\star * *}$ & $-0.234^{* * *}$ & $-0.240^{* * *}$ & -0.133 \\
\hline & $(-4.01)$ & $(-4.06)$ & $(-3.33)$ & $(-4.27)$ & $(-1.62)$ \\
\hline \multirow[t]{2}{*}{ treat3 } & $-0.473^{* * *}$ & $-0.604^{* * *}$ & $-0.475^{* * *}$ & $-0.244^{* * *}$ & $-0.201^{\star *}$ \\
\hline & $(-7.11)$ & $(-6.43)$ & $(-6.17)$ & $(-3.96)$ & $(-2.47)$ \\
\hline \multirow[t]{2}{*}{ treat 4} & $-0.234^{* * *}$ & $-0.349^{* * *}$ & $-0.572^{\star * *}$ & $-0.482^{* * *}$ & 0.020 \\
\hline & $(-3.65)$ & $(-4.51)$ & $(-7.38)$ & $(-6.99)$ & $(0.22)$ \\
\hline control variables & no & no & yes & yes & yes \\
\hline$N$ & $4,115,475$ & $3,732,586$ & $4,115,475$ & $4,115,475$ & $4,115,475$ \\
\hline
\end{tabular}

$t$ statistics in parentheses; ${ }^{\star} p<0.1,{ }^{* *} p<0.05,{ }^{* *} p<0.01$. 
In Table 5, the time interval of columns (1) to (3) is Semi-annual, that is, half a year between two adjacent periods (e.g., between Treat1 and Treat2). From columns (1) to (3), in order to investigate the results under different conditions, we successively cluster to individual, cluster to industry, and control the individual fixed effect and time fixed effect respectively. It can be seen from the results of these three columns that the coefficients of the variables treat $_{i t}^{-4}-$ treat $_{i t}^{-1}$ (before the publication of list) are basically not significant, but noting that the coefficients of the variables after publication of the list have changed from the non-significant before to significant, and the coefficients are all negative, consistent with the results of static model. This indicates that the DID models in this paper satisfies the parallel trend hypothesis, and the results of the static model of DID are highly reliable. In order to make the results more robust, columns (4) and (5) further investigate the empirical results on condition that the interval between two periods (e.g., between Treat1 and Treat2) is quarterly and weekly respectively, and it is found that the coefficients before the publication of list are still insignificant while the coefficients after the publication of list begin to be significant.

Therefore, the conjecture at the beginning of this paper is confirmed: the inclusion of the MSCI index does lead to a decrease in stock trading activity. This result can be explained in the following two aspects:

Firstly, turnover rate represents the length of the holding period of investors in the stock market. For a long time, China's stock market is dominated by retail investors, and the level of dividends is low, so relatively the speculative atmosphere is very serious, which correspond to a high turnover rate. After China A-shares were included in MSCI index, a large number of global institutional investors entered into China A-share market. Compared with Chinese investors, institutional investors in developed countries have a more stable investment style, and relatively they prefer value investment more than speculation. More importantly, a large part of these newly entered foreign institutional investors are passive funds, which have been passively allocated to the stocks of the MSCI index for a long period of time, resulting in a decline in stock turnover rate and trading activity after the inclusion of the MSCI index.

Meanwhile, the turnover rate also represents the difference in the beliefs of all investors in the stock market. A high turnover rate indicates that investors have large divergences on the investment value of this stock, which leads to more frequently trading. The inclusion of MSCI index is a highly recognition of these component stocks by the global capital market, so investors have more consistent views on the investment value of these constituent stocks, which leads to a decrease in the turnover rate of stocks and a decline in trading activity after the inclusion of MSCI index.

\section{Conclusions and Policy Recommendations}

This paper takes all China's A-share stocks as samples and covers all trading days in four years from 2016 to 2019 to study whether the inclusion of MSCI in- 
dex has improved the activity of China's A-share stocks. The main conclusion of this paper is that the inclusion of MSCI index does reduce the turnover rate of stocks and the degree of trading activity. On the one hand, after the inclusion of MSCI index, a large number of institutional investors, especially passive funds from developed countries, have entered into China's A-share market. They have more stable investment style and longer term capital; on the other hand, the inclusion of the MSCI index is a highly recognition from the global capital markets for these component stocks, so investors' views on the value of these constituent stocks have become relatively more consistent. For these two reasons, the turnover rate of these stocks in China A-shares has significantly decreased after being included in the MSCI index, and the trading activity has also decreased.

Based on this, this paper suggests that China should seize the important opportunity of A-shares being included in the MSCI index, give full play to the benefits brought by the opening-up of the capital market, actively guide the transformation of the investment concept of the stock market, and better play the function of capital pricing and capital allocation of the stock market.

\section{Conflicts of Interest}

The author declares no conflicts of interest regarding the publication of this paper.

\section{References}

Brennan, M. J., Chordia, T., \& Subrahmanyam, A. (1998). Alternative Factor Specifications, Security Characteristcs and the Cross-Section of Expected Stock Returns. Journal of Financial Economics, 49, 345-373.

Chen, T. Y. (2019). The Impact of A-Shares Inclusion in the MSCI Index on China's Stock Market. Wuhan: Central China Normal University.

Chordia, T., Subrahmanyam, A., \& Anshuman, V. R. (2001). Trading Activity and Expected Stock Returns. Journal of Financial Economics, 59, 3-32. https://doi.org/10.1016/S0304-405X(00)00080-5

Datar, V. T., Naik, N. Y., \& Radcliffe, R. (1998). Liquidity and Stock Returns: An Alternative Test. Journal of Financial Markets, 1, 203-219. https://doi.org/10.1016/S1386-4181(97)00004-9

De Gaetano, D. (2018). Forecast Combinations for Structural Breaks in Volatility: Evidence from BRICS Countries. Journal of Risk and Financial Management, 11, 64. https://doi.org/10.3390/jrfm11040064

E, Z. H., \& Su, J. (2017). The Significance and Influence of A-Share Inclusion in MSCI. Financial View, No. 7, 50-51. (In Chinese)

Ge, F. (2018). The Inclusion in MSCI Index of A-Shares Speeds Up the Improvement of Market. China Economic Weekly, No. 21, 3. (In Chinese)

Guo, S. L. (2019). The Effect of Secondary Expansion after A-Shares' Inclusion in the MSCI Index. Money, No. 10, 36-37. (In Chinese)

Joyo, A. S., \& Lefen, L. (2019). Stock Market Integration of Pakistan with Its Trading Partners: A Multivariate DCC-GARCH Model Approach. Sustainability, 11, 303. https://doi.org/10.3390/su11020303 
Kong, Y. W. (2018). Analysis of the Influence of A-Shares Has Been Included into the MSCI Index on the Price of Industry Leading Stocks. Shanghai: Shanghai International Studies University.

Li, J. P. (2018). How Do A-Shares Benefit from MSCI Inclusion? Study of the Shenzhen-Hong Kong Stock Connect System Using the Counterfactual Evaluation Method. Financial Economics Research, 33, 77-86.

Mo, K. W. (2018). Opportunities and Challenges Coexist after A-Shares Including into MSCI. Modern Commercial Banking, No. 12, 76-77. (In Chinese)

Singh, J., Ahmad, W., \& Mishra, A. (2019). Coherence, Connectedness and Dynamic Hedging Effectiveness between Emerging Markets Equities and Commodity Index Funds. Resources Policy, 61, 441-460. https://doi.org/10.1016/j.resourpol.2018.03.006

Su, D. W., \& Mai, Y. X. (2004). Liquidity and Asset Pricing: An Empirical Exploration of Turnover and Expected Returns on Chinese Stock Markets. Economic Research Journal, No. 2, 95-105.

Wei, Z. (2017). The Impact of A-Shares' Inclusion in MSCI Index. China Finance, No. 18, 52-55. (In Chinese)

Zhang, Z., \& Liu, L. (2006). Turnovers and Stock Returns: Liquidity Premium or Speculative Bubbles? China Economic Quarterly, No. 2, 871-892. 